\title{
Role of Voice Therapy in Patients with Mutational Falsetto
}

\author{
${ }^{1}$ Arvind Varma, ${ }^{2}$ Alok Kumar Agrahari, ${ }^{3}$ Raj Kumar, ${ }^{4}$ Vijay Kumar
}

\begin{abstract}
Background: Mutational falsetto is the most common mutational voice disorder, found in all ages. Clinicians often miss this diagnosis due to unfamiliarity with the condition. The voice of a person with mutational falsetto is high pitched, weak, thin, breathy, hoarse and monopitched.
\end{abstract}

Objective: This study was carried out to evaluate the efficacy of voice therapy in persons with mutational falsetto.

Methods: Eleven male patients with ages between 18 and 26 years (mean age 22.18 years, SD 2.52) diagnosed with mutational falsetto underwent acoustical analysis using Praat Software, perceptual analysis using grade, roughness, breathiness, asthenia and strain (GRBAS) scale and psychosocial analysis using emotional component of voice handicap index (VHI). All the components were analyzed pre- and postvoice therapy.

Results: Improvement in acoustic analysis parameters was statistically significant with p-value less than 0.0001 (pretherapy mean of fundamental frequency (F0) was 217.45 with SD 8.68, whereas post-therapy mean of $F 0$ was 127.50 with SD 5.32). Significant improvement in perceptual analysis was seen post-therapy on GRBAS scale. Improvement in psychosocial aspect was also statistically significant with $p$-value less than 0.0001 (pre-therapy mean 26.18, SD 1.72 post-therapy mean 7, SD 1.15).

Conclusion: Voice therapy plays an important role in lowering FO and alleviation mental agony of the patients with mutational falsetto.

Keywords: Fundamental frequency, Mutational falsetto, Voice therapy.

How to cite this article: Varma A, Agrahari AK, Kumar R, KumarV. Role of Voice Therapy in Patients with Mutational Falsetto. Int J Phonosurg Laryngol 2015;5(1):25-27

Source of support: Nil

Conflict of interest: None

\section{INTRODUCTION}

Mutational falsetto voice is conspicuously high pitched and casts doubt on the masculinity and maturity of speaker. It can result in severe psychological disturbance due to emotional, social and professional related difficulty in day to day life.

${ }^{1}$ Assistant Professor, ${ }^{2}$ Senior Resident, ${ }^{3,4}$ Audiologist and Speech Therapist

${ }^{1-4}$ Department of ENT, Shri Guru Ram Rai Institute of Medical and Health Sciences, Dehradun, Uttarakhand, India

Corresponding Author: Arvind Varma Varma, Assistant Professor, Department of ENT, Shri Guru Ram Rai Institute of Medical and Health Sciences, Dehradun, Uttarakhand, India Phone: 9627786755, e-mail: drvarmaarvind@gmail.com
The mutational period of human development represents dramatic physical and emotional transformation of the individual. Principal changes that take place during puberty are as follows:

- Considerable increase in vital capacity secondary to increase in the size and strength of thoracic muscles.

- An increase in length and width of neck.

- A descent of larynx producing greater length and width of pharynx thus, enlarging the resonatory system.

The basic difference between the pubertal development of the male and female larynx has to do with direction of the growth. Until puberty, they are essentially the same in size and form; however, during pubertal development, male larynx grows especially in antero-posterior direction leading to protrusion of thyroid eminence also known as Adam's Apple. ${ }^{1}$ The female larynx increases in height greater than width, the results in both sexes being a deepening of the voice and greater vocal power. The general trend of mutational voice changes is downward direction of pitch. Investigation of pubertal changes of singing voice have led to agreement that the lower limit of girl's voice descends one and two tones and the upper limit may gain the same. The lower limit of boy's voices descends a full octave. The transformation of the boys' voice during mutation seems to take following directions: a gradual lowering of the lower limit with steadiness of higher tones, then steadying of low notes (main phase), followed by stabilization of the low notes marking the end of the mutational period.

Symptoms of mutational falsetto voice are high pitched, weak, thin, breathy, hoarse and monopitched giving the overall impression of immaturity, effeminacy and passiveness. On laryngoscopic examination, the larynx is structurally normal.

\section{MANAGEMENT}

Mutational falsetto has been treated by the following methods:

- Voice therapy

- Laryngeal manipulation

- Laryngeal surgery

Voice therapy plays an important role in treatment of mutational falsetto. The aim of voice therapy is to lower the fundamental frequency (F0). Fundamental frequency corresponds with the rate of oscillation of vocal folds (expressed in $\mathrm{Hz}$ ) and is a primary factor in perception of pitch. 


\section{OBJECTIVE}

To evaluate efficacy of voice therapy in person with mutational falsetto.

\section{METHODS}

The present study was carried out in ENT department of a tertiary care center and teaching institute from March 2012 to 2015. The subjects consisted of 11 male patients with age range 18 to 26 years (mean age 22.18 years) who reported to the department with complaint of feminine voice. This study was approved by ethical committee of institution and informed consent was obtained from all the participants.

\section{Inclusion Criteria}

- Male with feminine voice with high F0 as analyzed on Praat software.

- Normal larynx on laryngoscopy using $90^{\circ} \mathrm{Karl}$ Storz laryngoscope.

\section{Exclusion Criteria}

- Abnormal findings on laryngoscopy

- Transgender

\section{Acoustic Analysis}

All subjects' voice was recorded in an acoustically treated room as measured by sound level meter LUTRON SL4010 using Wave Pad Software from a distance of $15 \mathrm{~cm}$ from microphone both pre- and post-therapy. The subjects were asked to say the same phonetically balanced text in local language pre- and post-therapy in habitual voice. The mean F0 of each text, pre-therapy and post-therapy was analyzed using Praat Software.

\section{Perceptual Analysis}

Perceptual analysis was done using GRBAS scale by another speech language therapist with voice expertise other than the therapist who conducted voice therapy. The age and gender of the subjects were informed to the therapist. The pre- and post- pre-recorded voices were presented to the therapist in random order. GRBAS scale measures grade, roughness, breathiness, asthenia and strain of the voice. Each of the five categories is graded from 0 (no perceived abnormality) to 3 (severe abnormality). ${ }^{2}$

\section{Psychosocial Analysis}

This was done using emotional section of the voice handicap index (VHI) questionnaires pre- and post- therapy. Voice handicap index was developed and validated by Jacobson, Johnson, Gergnlski, Silbergleit and Beginner in 1997. First version of VHI had 85 items, which was reduced to 30 items scale as VHI-30. It consists of functional, physical and emotional sections. Each section of VHI weighs a score of 40 , which gives total of 120. Voice handicap index score of 0 to 30 represents low score indicating minimal amount of handicap associated with the voice disorders. A score of 31 to 60 denotes moderate amount of handicap due to voice problem. A VHI score is 61 to 120 represents significant and serious amount of voice handicap due to voice disorders, often seen in patients with new onset vocal fold paralysis or severe vocal fold scarring. ${ }^{3}$

\section{Voice Therapy Protocol used for the Study}

All patients underwent voice therapy schedule with following technique:

- Glottal attack-phonation of vowel sounds with glottal attack, i.e. forceful initiation of voice during production of vowels

- Humming while gliding down the pitch scale

- Production of glottal fry, i.e. lowest possible pitch which patients can produce

- Use of vegetative sounds

- Digital manipulation of thyroid cartilage during vowel production-patients are taught to apply a gentle inward push on the anterior aspect of thyroid cartilage while sustaining a vowel.

- Inspiratory phonation

The frequency of therapy consisted of two sessions per week of half an hour duration each. The patients were allowed to note the difference between habitual pitch and new pitch and were counseled to accept 'new voice' as their own voice. The lower pitch was stabilized using standard therapy. Once the newly acquired pitch had stabilized, the patients were re-evaluated for acoustic, perceptual and psychosocial improvement.

\section{RESULTS}

The number of sessions required to achieve desired results varied depending on the patient's F0, compliance and motivation during therapy. Out of our 11 patients, two could achieve pitch level in two sessions; five needed four sessions; four patients needed five sessions.

\section{Acoustic Analysis}

Mean F0 was assessed pre- and post-therapy for all patients. The average pre-therapy mean F0 was $217.45 \mathrm{~Hz}$, SD 8.68 and the post-therapy mean F0 was $127.50 \mathrm{~Hz}$, SD 5.32. The two-tailed $\mathrm{p}$-value was found to be less than 0.0001 which is statistically significant. 


\section{Perceptual Analysis}

On the GRBAS scale, all the patients had abnormal scoring pre-voice therapy while post-voice therapy all the patients showed normal scoring that is G0 R0 B0 A0 S0.

\section{Psychosocial Analysis}

The mean of emotional component of VHI pre-therapy was 26.18 , SD 1.72, whereas post-therapy, it was 7, SD 1.15. The two-tailed p-value was calculated to be less than 0.0001 which is statistically significant.

\section{DISCUSSION}

Mutational falsetto is found in patients of all ages, some as young as 14 or 15 years. They are either brought by parents or later in life volunteering themselves for help after long struggle with the social and psychological handicap of voice that does not match gender or sounds infantile. Clinicians often miss the diagnosis of mutational falsetto because of unfamiliarity with the syndrome. Yet it is one of the easiest and most rewarding disorders to treat. ${ }^{1}$

In this study, two of 11 patients could achieve satisfactory frequency level in two sessions while five needed four sessions and four patients needed five sessions to lower the frequency to conversational level. These variations in the number of sessions might be due to the patients showing different level of vocal plasticity. These findings are almost similar to Desai V et al. ${ }^{4}$

As for the results obtained, they show that mean F0 of the patients with mutational falsetto can be reduced to a significant level using voice therapy.

According to the results of our study, all patients obtained a better voice after therapy. This is in corroboration with the study previously carried by Dagli $\mathrm{M}$ et al, ${ }^{5}$ Alam $\mathrm{N}$ et al. ${ }^{6}$

A study done by Hammarberg B et $\mathrm{al}^{7}$ which consisted of 10 patients of mutational falsetto, in pre- and posttherapy condition showed mean F0 values of $221 \mathrm{~Hz}$ and $119 \mathrm{~Hz}$ respectively, which is similar to our study.

Another study done by Cassol $\mathrm{M}$ et $\mathrm{al}^{8}$ consisting of 45 subjects of mutational falsetto showed significant decrease I F0 after 6 months of voice therapy.
In our study, GRBAS score significantly improved in all the participants after the intervention, corroborating other studies. ${ }^{5,7,8}$

In this study, voice therapy also helped to enhance confidence and self image of the speaker due to psychosocial improvement which is confirmed by decrease in emotional component of VHI score. These findings are similar to a study done by Alam $\mathrm{N}$ et al. ${ }^{6}$

Further studies consisting of larger group of patients are needed with newer techniques of acoustic analysis and quality of life measures to confirm the results and to improve our understanding about mutational falsetto.

\section{CONCLUSION}

Voice therapy plays an important role in treatment of patients with mutational falsetto by lowering F0, and thereby alleviating the psychological agony these patients face in their life.

\section{REFERENCES}

1. Aronson AE, Bless DM. Clinical voice disorders. 4th ed. Thieme Publication. 2009. p. 184-187.

2. Voice: assessment and management. Proceedings of the national workshop held on 14-15 February 2008. p. 72.

3. Hedge M, Achala C, Bhat S. Voice Handicap index: a comparison of clinician's ratings and self rating by individuals with dysphonia. JAIISH 2009;28:25-30.

4. Desai V, Mishra P. Voice therapy outcome in puberphonia 2012;2(1):26-29.

5. Dagli M, Sati I, Acar A, et al. Mutational falsetto: intervention outcomes in 45 patients. J Laryngol Otol 2008 Mar; 122(3):277-281.

6. Alam N, Sinha V, et al. Efficacy of voice therapy for treatment of puberphonia: review of 20 cases. World Articles in Ear Nose Throat 2012;5(1).

7. Hammarberg B. Pitch and quality characteristics of mutational voice disorders before and after therapy. Folia Phoniatr 1987;39(4):204-216.

8. Cassol M, Denardin ID. Perceptual assessment and acoustic voice in mutational falsetto: a case study. Pro-Fono 2000; 12(1):76-81. 